\title{
A Importância dos Sedimentos no Ciclo de Poluentes Metálicos no Meio Aquático
}

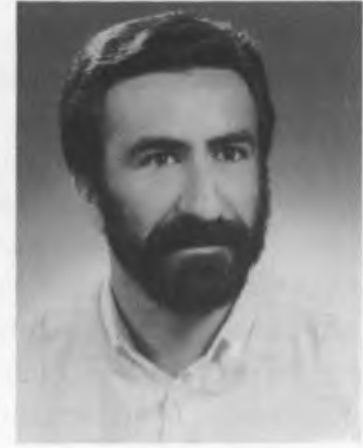

Carlos Vale

Licenciatura em Engenharia Química (IST).

Investigador (Oceanografia Química).

Membro de grupos de trabalho internacionais no domínio da química marinha.

Trabalhos desenvolvidos nos seguintes temas: estuários, sedimentos, poluentes e nutrientes.

O rio faz e desenha o seu leito; a partir daí fica escravo dele.

Poeta espanhol

A quantidade de sedimentos transportada anualmente pelos rios é estimada em cerca de 15 mil milhões de toneladas (Milliam \& Meade, 1983). Contudo, grande parte dos sedimentos nunca atinge o oceano aberto, ficando retidos nas margens dos continentes e formando os depósitos de estuários e zonas costeiras. Para além dos materiais resultantes da erosão natural dos continentes, nas últimas décadas vêm sendo lançados no meio aquático desperdícios resultantes da actividade do Homem. Este acréscimo de materiais de proveniência antropogénica, tem provocado alterações mais acentuadas na composição das partículas em pequenos rios e estuários em cujas margens se encontram instaladas cidades e zonas industriais. Pelo contrário, a composição química dos sedimentos transportados pelos grandes rios do mundo mantém-se comparável à da crosta terrestre (Martin \& Meybeck, 1979).

No passado, o lançamento de desperdícios para os rios e estuários era baseado na hipótese de que estes materiais seriam transportados para o oceano e aí dispersos. Actualmente, pensa-se que a realidade é diferente. Grande parte dos poluentes fica retida nos estuários e zonas costeiras.

$\mathrm{O}$ transporte de metais pesados pelos rios é feito principalmente na forma particulada (Gibbs, 1973). Esta associação deve-se à baixa solubilidade dos metais e à sua fácil adsorção às fases particuladas, quer de origem litogénica quer biogénica. Nos estuários a remoção dos metais para a fase particulada é também muito intensa (Liss, 1976). O aumento de salinidade durante a mistura das águas nos estuários leva à floculação de óxidos de ferro, de algumas substâncias húmicas e de outras partículas coloidais, como sejam as argilas (Dyer, 1972). Muitos metais-traço ficam adsorvidos a estas argilas ou coprecitam com o ferro, sendo depositados em conjunto com as partículas formadas no interior dos estuários. A produção de partículas fecais pelos organismos filtradores e a incorporação de metais nos seus tecidos (Goldberg \& Martin, 1983) pode também aumentar a sua remoção da fase dissolvida nestes locais.

A hipótese defendida por Turekian (1977), de que alguns estuários se comportam como eficientes ratoeiras retendo os metais no seu interior, começou a ser encarada como válida para diversos tipos de estuários. O destino dos metais nos sistemas fluvio- estuarinos foi, portanto, considerado como estando relacionado com o transporte e destino final dos sedimentos. Serão, no entanto, os elementos de origem antropogénica incorporados nos sedimentos de uma forma «permanente» ou apenas temporária? Serão os poluentes transferidos para a água após a sedimentação, à semelhança dos nutrientes como o azoto e o fósforo? Ou, pelo contrário, serão remobilizados no interior dos sedimentos, como ocorre com a redistribuição de alguns elementos que leva à formação de nódulos polimetálicos no fundo dos oceanos? Face a estas questões o estudo dos ciclos dos poluentes metálicos no meio aquático passou a englobar as trocas ocorridas através da interface sedimento-água (Berner, 1980).

"anstituto Nacional de Investigação das Pescas, Av. Brasília, 1400 Lisboa. 


\section{Sistema sedimento-água}

A descrição sumária dum sistema sedimento-água é apresentada na Figura 1. Podem distinguir-se quatro reservatórios abióticos para os micropoluentes: as partículas em suspensão, a água, os sedimentos e a água intersticial dos sedimentos (Salomons, 1985). Estes reservatórios não são independentes e interactuam entre si. Entre as partículas em suspensão e os poluentes em solução têm lugar processos designadamente de adsorção/desadsorção e de coprecipitação. As partículas em suspensão e os sedimentos depositados estão ligados através de processos de erosão e sedimentação. Entre os sedimentos e os metais na água intersticial ocorrem processos de adsorção/desadsorção e de precipitação/dissolução. A elevada concentração de metais na água intersticial dos sedimentos, pode influenciar os níveis destes elementos na água através de processos como a difusão molecular (Berner, 1980).

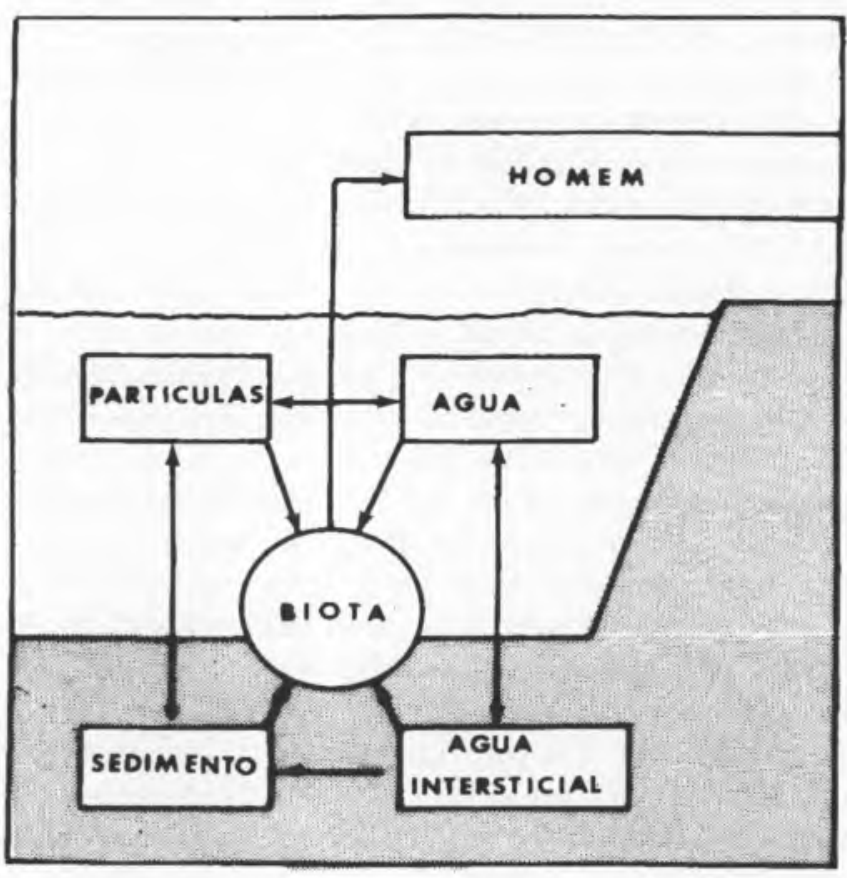

FIGURA 1

Representação esquemática das interacçôes dos poluentes no meio aquático (Salomons, 1985)

\section{Interacção poluente-partículas em suspensão}

A mobilidade e a toxicidade dos metais estão dependentes da forma em que estes se encontram no meio aquático (fase dissolvida versus fase particulada). A quantidade de partículas em suspensão ao longo dum estuário passa normalmente por um máximo (Postma, 1967) e, portanto, a remoção de metais para a fase particulada pode mudar entre o início e o fim do estuário. No entanto, a concentração de partículas pode flutuar em pequenas escalas de tempo, por exemplo horas (Vale \& Sundby, 1987), pelo que a associação de metais às partículas está fortemente relacionada com as condições hidrodinâmicas. A presença, num estuário, de uma zona de turbidez máxima pode induzir uma crescente remoção de metais para a fase particulada. Contudo, o aumento de clorinidade, levando à formação de cloro-complexos (por exemplo de $\mathrm{Cd}$ ), reduz a associação destes elementos à fase sólida. O posicionamento da zona de maior turbidez relativamente ao local em que ocorre o aumento de clorinidade pode, de certa forma, determinar o resultado da acção conjunta destes dois factores. Balls (1989) mostrou que, em esutários de elevada turbidez, o coeficiente de distribuição (definido como a razão entre as concentrações de um determinado metal na fase dissolvida e na particulada) varia inversamente com a quantidade de partículas em suspensão. Isto significa que, apesar dos diversos factores que influenciam a interacção poluente-partículas, a quantidade de partículas num estuário desempenha um papel preponderante na remoção dos poluentes da fase dissolvida.

A matéria em suspensão é uma mistura complexa da várias partículas (minerais de argila, carbonatos, quartzo, feldspatos e matéria orgânica) com diferentes capacidades para a adsorção de metais. No entanto, a incorporação de poluentes é principalmente influenciada pelas propriedades da superfície das partículas, que em ambiente salino, tendem a ficar cobertas por um filme orgânico macromolecular (Balistrieri et al, 1981). Não é, por isso, fácil distinguir, num estuário a diferente incorporação de metais pelos vários tipos de partículas em suspensão.

As características hidrodinâmicas estuarinas levam a uma deposição fraccionada de partículas. Enquanto que as partículas de maiores dimensões tendem a movimentar-se no interior do estuário de acordo com ciclos periódicos de erosãosedimentação (Vale \& Sundby, 1987), as de dimensões mais reduzidas (ou menos densas) podem atravessar o estuário permanentemente em suspensão (Duinker, 1983). A concentração de metais-traço nestes dois tipos de partículas é normalmente diferente. As que permanecem em suspensão de uma forma mais ou menos permanente, apresentam geralmente um maior conteúdo em metais do que as que são periodicamente ressuspendidas e depositadas (Vale, 1989). Apesar de não ser fácil registar alterações na composição elementar das partículas, devido à repetida erosão-sedimentação, devem ocorrer frequentes mudanças na decomposição da matéria orgânica no decorrer destes ciclos. Morris et al (1982) explicaram as alterações nos níveis de manganês dissolvido registados junto ao fundo, pela destruição dos óxidos de manganês no sedimento e pela difusão de manganês dissolvido.

\section{Processos ocorridos nos sedimentos: diagénese primária}

As condições existentes nos sedimentos são drasticamente diferentes das encontradas na água. Enquanto que na água o oxigénio dissolvido existe em quantidade suficiente, para ser consumido nas reacções de oxidação que aqui têm lugar (a quase totalidade dos estuários e zonas costeiras é bem oxigenada), nos sedimentos o oxigénio existe apenas nos primeiros milímetros (Revsbech et al, 1980). Outros oxidantes são portanto utilizados na degradação do material depositado. A oxidação da matéria orgânica nos sedimentos tem lugar segundo uma sequência redox bem conhecida esquematicamente apresentada na Figura 2 (Froelich et al, 1979). À superfície do sedimento o $\mathrm{O}_{2}$ é utilizado como oxidante. À medida que a sua concentração diminui, com a profundidade, 
são utilizados sequencialmente outros oxidantes, o $\mathrm{NO}_{3}^{-}$, o $\mathrm{MnO}_{2}$, depois o $\mathrm{FeOOH}$, etc. No entanto, nem sempre estas reacções ocorrem em camadas distintas do sedimento e esta sequência vertical é frequentemente mascarada. Contribuem para estas alterações a perturbação do fundo por processos físicos, como a ressuspensão da camada superficial do sedimento e a perfuração do sedimento pelos animais que vivem no seu interior (Aller, 1977).

Os metais-traço associados às partículas em suspensão na água podem ficar «permanentemente» retidos no fundo quando estas depositam. A sedimentação actua, neste caso, como um processo de remoção de poluentes da água. A incorporação no fundo pode resultar do facto de, no interior do sedimento, alguns metais adquirirem formas estáveis. Por exemplo alguns metais existentes na forma de óxidos nas partículas passam a sulfuretos nos sedimentos (Stumm \& Morgan, 1981).

Outros elementos são libertados dos sedimentos para a água intersticial, no seguimento da destruição das estruturas que os arrastaram da coluna de água e difundidos de novo para a água. Em consequência destas alterações, desenvolvem-se geralmente fortes gradientes nas concentrações de metais junto à interface sedimento-água (Berner, 1980). O transporte das espécies sensíveis aos gradientes redox faz-se com maior intensidade junto da interface óxica/anóxica (normalmente próxima da superfície do sedimento). Os exemplos clássicos são o manganês e o ferro (Sundby \& Silverberg, 1985; Davison \& Woof, 1984). A concentração destes elementos na água intersticial dos sedimentos é controlada por reacções de precipitação-dissolução. Isto é, a concentração na água intersticial é independente da existente nos sedimentos. Para outros elementos-traço os mecanismos são menos conhecidos, admitindo-se que a concentração na água intersticial seja determinada por processos de adsorção/desadsorção. Ou seja, as concentrações nos sedimentos e na água intersticial não são independentes. Este relacionamento tem repercussões importantes do ponto de vista ambiental, porque significa que a retenção destes poluentes nos sedimentos tende a ser limitada. Contudo, tem-se verificado que os óxidos de ferro e manganês recentemente formados, adsorvem facilmente muitos metais-traço (Johnson, 1986). O transporte dos metais da água intersticial dos sedimentos para a água de superfície pode, portanto, ser reduzido pela adsorção aos óxidos de ferro e manganês recentemente precipitados na camada superficial do sedimento. Esta retenção no interior do sedimento tende a diminuir o refluxo dos metais para a água. Ao diminuir as trocas entre o sedimento e a coluna de água esta fixação apresenta, por isso, uma acção benéfica para os organismos que aí vivem.

Estes poluentes podem, no entanto permanecer disponíveis para os organismos que habitam o sedimento. A concentração de metais de origem antropogénica em bibalves e plantas do sedimento está correlacionada com a quantidade de metais ligada aos óxidos de ferro e manganês nos sedimentos (Campbell \& Tessier, 1989). Isto parece sugerir que apenas os metais que se encontram nesta fracção ficam disponíveis para a biota.

Os organismos podem ter um papel mais activo e serem um factor geoquímico importante. A perfuração e mistura dos sedimentos pelos animais que aí habitam aumenta a penetra- ção do oxigénio e, portanto, a superfície oxidada do sedimento. Isto origina um incremento das trocas através da inferface sedimento-água (Aller, 1977). As plantas dos sapais transportam oxigénio da atmosfera para as raízes e o excesso é expelido para as zonas anóxicas do sedimento. Este processo cria micro- ambientes oxidantes em zonas redutoras do sedimento onde precipitam hidróxidos de ferro e de manganês (Vale et al, 1989). Exemplos do papel desenvolvido pelas bactérias são, a metilação do mercúrio e do estanho, e a redução do sulfato que pode levar à conversão de alguns metais em sulfuretos insolúveis. Os produtos excretados pelas células de algumas microalgas podem aumentar a capacidade de complexação da água intersticial.

Os sedimentos podem, pois, desempenhar um papel importante no ciclo dos poluentes e ter uma influência determinante na qualidade da água dos sistemas aquáticos.

matéria
orgânica

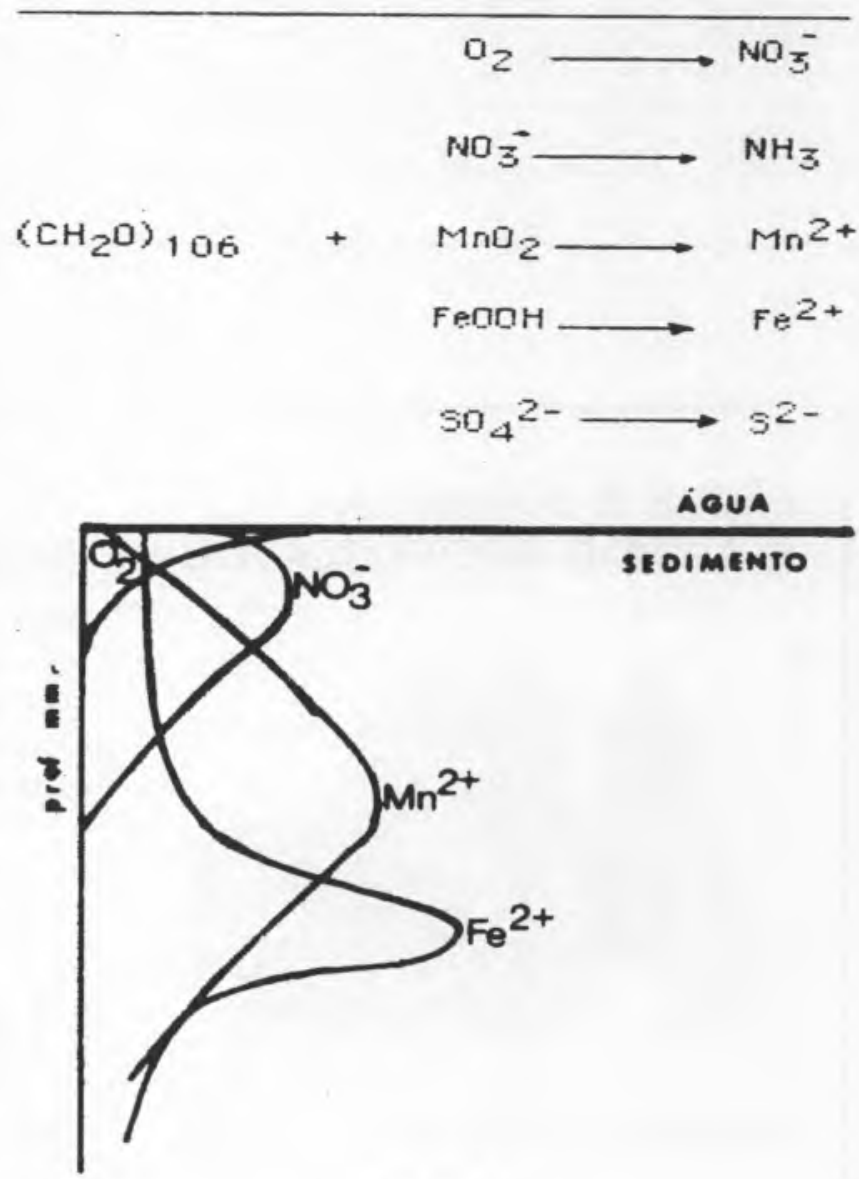

FIGURA 2

Sequência das reaçổes redox num sedimento não perturbado. $\left(\mathrm{CH}_{2} \mathrm{O}\right)_{106}$ é a abreviatura da composição da matéria orgânica marinha $\left(\mathrm{CH}_{2} \mathrm{O}\right)_{106}\left(\mathrm{NH}_{3}\right)_{16} \mathrm{H}_{3} \mathrm{PO}_{4}$ (Froelich et al, 1979)

\section{Referências}

- Aller, R. C., 1977. The influence of macrobenthos on chemical diagenesis of marine sediments. Ph. D. dissertation, Yale University, New Haven, Connecticut.

- Balistrieri, L., P. G. Brewer \& J. W. Murray, 1981. Scavening residence times of trace metals and surface chemistry of sinking particles in the deep ocean. Deep Sea Research, 28A: 101-121. 
- Balls, P.W., 1989. The partition of trace metals between dissolved and par ticulate phases in European coastal waters: a compilation of field data and comparison with laboratory studies. Netherl. J. Sea Research, 23, 1: 7-14.

- Berner, R. A., 1980. Early diagenese: a theoretical approach. Princeton Univ, Press. Princeton, 241 pp.

- Campbell, P. G. C. \& A. Tessier, 1989. Biological availability of metals in sediments: analytical approaches. In: Heavy metals in the Environment. Ed. J-P Vernet, 1:516-525.

- Davison, W. \& C. Woof, 1984. A study of the cycling of manganese and other elements in a seassonally anoxic lake, Rostherne Mere, UK. Wat. Res. 18, 6: 727-734.

- Duinker, J. C., 1983. Effects of particle size and density on the transport of metals to the Ocean. In: Trace metals in sea water. Eds. C. S. Wong, E. Boyle, K. W. Bruland, J. D. Burton \& E. D. Goldberg, 209-226.

- Dyer, K.R., 1972. Sedimentation in estuaries. In: The estuarine environment. Eds. R. S. K. Barnes \& J. Green, 10-32.

- Froelich, P.N., G. P. Klinkhammer, M. Bender, N. A. Luedtke, G. R. Heath, D. Cullen, P. Dauphin, D. Hammond, B. Hartman \& V. Maynard, 1979. Early oxidation of organic matter in pelagic sediments of eastern equatorial Atlantic: suboxic diagenesis. Geochim. Cosmochim. Acta, 43: 1075-1090.

- Johnson, C. A., 1986. The regulation of trace element concentrations in river and estuarine waters contaminated with acid mine drainage: the adsorption of $\mathrm{Cu}$ and $\mathrm{Zn}$ on amorphous $\mathrm{Fe}$ oxyhydroxides. Geochim. Cosmochim. Acta 50: 2433-2438.

- Gibbs, R. J., 1973. Mechanisms of trace metal transport in rivers. Sci. 180: 71-73.

- Goldberg, E. D. \& J. H. Martin, 1983. Metals in seawater as recorded by mussels. In: Trace metals in the sea water, Nato Conf. Serv., Ser IV: Marine Sciences, 9: 811-825.

- Liss, P. S., 1976. Conservative and non-conservative behaviour of dissol- ved constituents during estuarine mixing. In: Estuarine Chemistry. Eds. J: D. Burton \& P. S. Liss. 93-130.

- Martin, J.-M. \& M. Meybeck. 1979. Elemental mass-balance of material carried by major world rivers, Mar. Chem. /: 173-206.

- Milliam, J. D. \& R. M. Meade, 1983. World-wide delivery of river sediment to the oceans, J. Geol. 91, 1: 1-21.

- Morris, A. W., A. J. Bale \& R. J. M. Howland, 1982. The dynamics of estuarine manganese cycling. Est. Coast. Shelf. 14: 175-192.

- Postma, H., 1967. Sediment transport and sedimentation in estuarine environement. In: Estuaries. Ed. G. Lauff, Am. Assoc. Advanc. Sci., Publ. 83: $158-179$.

- Revsbech, N. P., J. Sorensen, T. H. Blackburn 6 J. P. Lomholt, 1980. Distribution of oxygen in marine sediments measured with microelectrodes. Limnol. Oceanogr. 25:403-411.

- Salomons, W. 1985. Sediments and wate quality. Envir. Tech. Let., 6. 315326.

- Stumm, W. \& J. J. Morgan, 1981. Aquatic Chemistry. J. Wiley \& Sons. 780 pp.

- Sundby, B. \& N. Silverberg, 1985. Manganese fluxes in the benthic boundary layer. Limnol. Ocean. 30, 2:372-381.

- Turekian, K. K. 1977. The fate of metals in estuaries. In: Estuaries, geophysics and the environment. Ed. Nat. Acad. Sci. Washington, DC, 121-127.

- Vale, C. \& B. Sundby, 1987. Suspended sediment fluctuations in the Tagus estuary on semi-diumal and fortnightly time scales. Est. Coast. Shelf Sci. 25: 495-508.

- Vale, C., 1989. Temporal variations of particulate metals in the Tagus river estuary. Sci. Tot. Envir. (in press).

- Vale,C.,F. M. Catarino, C. Cortesão \& M. I. Caçador, 1989. Presence of metal-rich rhizoconcretions on the roots of Spartina Maritima from the salt-marshes of the Tagus estuary (Portugal). Sci. Tot. Envir. (in press).
FECHE A TORNEIRA

E ABRA O RECIRCULADOR DE ÁGUA FRIA "NESLAB"

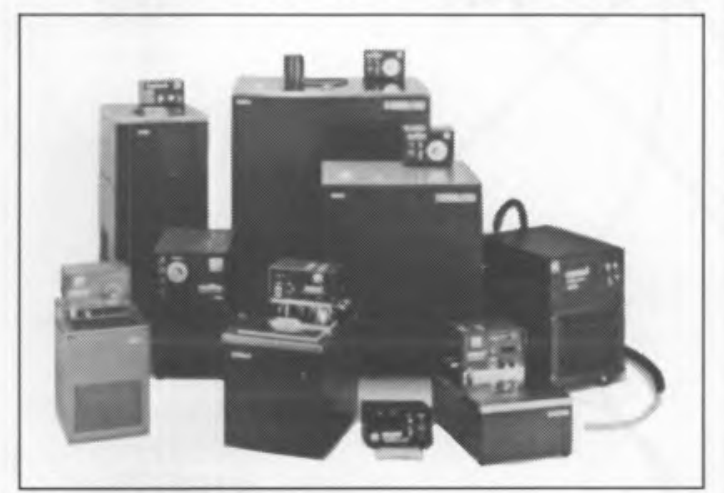

NESLAB INSTRUMENTS

FABRICA TAMBÉM:

REFRIGERADORES DE IMERSÃO ATÉ $-100^{\circ} \mathrm{C}$ BANHOS MARIA DE $-35^{\circ} \mathrm{C}$ a $120^{\circ} \mathrm{C}$ BANHOS CRIOSCÓPICOS E DE ALTA TEMPERATURA
Poupe água e dinheiro com os recirculadores de água refrigerada. Terá uma constante provișão de água refrigerante limpa, e à desejada temperatura e pressão.

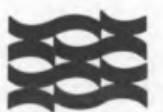

NESL国

\section{ELIMINE OS PROBLEMAS DE ÁGUA CORRENTE.}

Representante exclusivo:
PARA:

DIFRATÓMETROS
ESPECTROFOTROMETROS
MICRO-SONDAS
LASERS
CROMATÓGRAFOS
ULTRA CENTRIFUCAS
N2 LIQQUIDO
CO2 SOLIDO
TESTES DE PETROLLEO
REFRATÓMETROS
CURVAS DE FUSÃO
CRISTALIZAÇŌES
MICROCÓPIO ELECTRÓNICO
ETC...
MICRO-SONDAS

LASERS

CROMATÓGRAFOS

ULTRA CENTRÍFUCAS

$\mathrm{N}_{2}$ LIQQUIDO

$\mathrm{CO}_{2}$ SÓLIDO

TESTES DE PETRÓLEO

REFRATOMETROS

CURVAS DE FUSÃO

MICROCÓPIO ELECTRÓNICO ETC...
ESPECTROFOTROME

\section{Geoequipamentos-importação,lda. \\ EQUIPAMENTOS DE LABORATÓRIO}

$\mathrm{O}^{\circ} \mathrm{C}$ a $250^{\circ} \mathrm{C}$ 


\section{Convite à Reflexão}

\section{A Tecnologia e o Ambiente}

$\mathrm{O}$ choque do futuro - a doença da mundaça - pode ser evitado, mas para isso será precisa uma drástica acção social e, até, política. Seja como for que os indivíduos tentem regular o ritmo das suas vidas, sejam quais forem as muletas psíquicas que lhes ofereçamos, sejam quais forem as modificações que introduzamos no ensino, a sociedade como um todo não deixará de andar à deriva num turbilhão, até conseguirmos dominar o próprio impulso acelerativo.

A grande velocidade da mudança pode ser atribuída a muitos factores. Explosão demográfica, urbanização, desencontro das proporções de velhos e novos - tudo isto contribui. No entanto, o progresso tecnológico é indubitavelmente um ponto crítico do conjunto de causas. Pode até ser o centro vital que activa todos os outros factores. Portanto, uma táctica importante da luta para evitar o choque do futuro maciço implica a regularização consciente do progresso tecnológico.

Não podemos nem devemos deter esse progresso. Só os idiotas românticos dizem tolices acerca de regressar a um «estado de natureza». Um estado de natureza é aquele em que as crianças definham e morrem à míngua de cuidados médicos elementares, em que a malnutrição entrava o desenvolvimento do cérebro, em que, como Hobbes nos recordou, a vida predominante é «pobre, rude, embrutecedora e breve». Virar as costas à tecnologia seria, além de estúpido, imoral.

Se é verdade que um grande número de homens ainda vive, metaforicamente, no século XII, quem somos nós para encarar, sequer, a ideia de atirarmos fora a chave do desenvolvimento económico? Àqueles que lançam pela boca fora idiotices antitecnológicas em nome de vagos «valores humanos», deve-se perguntar: De que humanos? Atrasar deliberadamente o relógio seria condenar milhares de milhões de pessoas a uma miséria permanente e forçada, no momento preciso em que a sua libertação se está a tornar possível. É evidente que não precisamos de menos tecnologia: precisamos de mais. Ao mesmo tempo, não deixa de ser verdade que, muitas vezes, aplicamos a nova tecnologia estúpida e egoisticamente. Na nossa pressa de tirar vantagens económicas imediatas da tecnologia, transformámos o nosso ambiente num barril de pólvora físico e social.

A aceleração da difusão; o carácter auto-reforçante do progresso técnico graças ao qual cada passo em frente facilita não um, mas muitos outros passos em frente; a relação íntima entre tecnologia e ordem social - tudo isto cria uma forma de poluição psicológica, uma aceleração aparentemente impossível de deter do rimo de vida. À poluição psíquica junta-se o vómito industrial que conspurca os nossos mares e o nosso céu. Pesticidas e herbicidas infiltram-se nos nossos alimentos; carcaças amachucadas de automóveis, latas de alumínio, garrafas, embalagens perdidas e plásticos sintéticos formam uma montureira imensa, à medida que um número cada vez maior dos nossos detritos resiste à decomposição. Ainda não imaginamos, sequer, o que devemos fazer as desperdícios radioactivos: injectá-los no solo, dispará-los para o espaço exterior ou lançá-los nos oceanos?

O nosso poder tecnológico aumenta, mas os seus efeitos secundários e os seus riscos potenciais também aumentam. Arriscamo-nos a provocar a termopoluição dos próprios oceanos, a sobreaquecê-los, a destruir quantidades incomensuráveis de vida marinha e até a fundir, talvez, as calotas polares. Em terra, concentramos massas tão grandes de gente em ilhas urbano-tecnológicas tão pequenas, que corremos o risco de consumirem o oxigénio do ar mais depressa do que ele possa ser substituído, do que resultaria a possibilidade de surgirem novos Saras onde agora existem cidades. Com tais perturbações da ecologia natural, é possível que, segundo as palavras do biólogo Barry Commoner, estejamos literalmente «a destruir este planeta como lugar adequado para a habitação humana».

\section{SPQ - QUOTAS}

Sócio Efectivo

Estudante

\section{BOLETIM}

Assinatura (4 números)

$1500 \$ 00$ (no país)

US\$35 (no estrangeiro)

Número avulso 


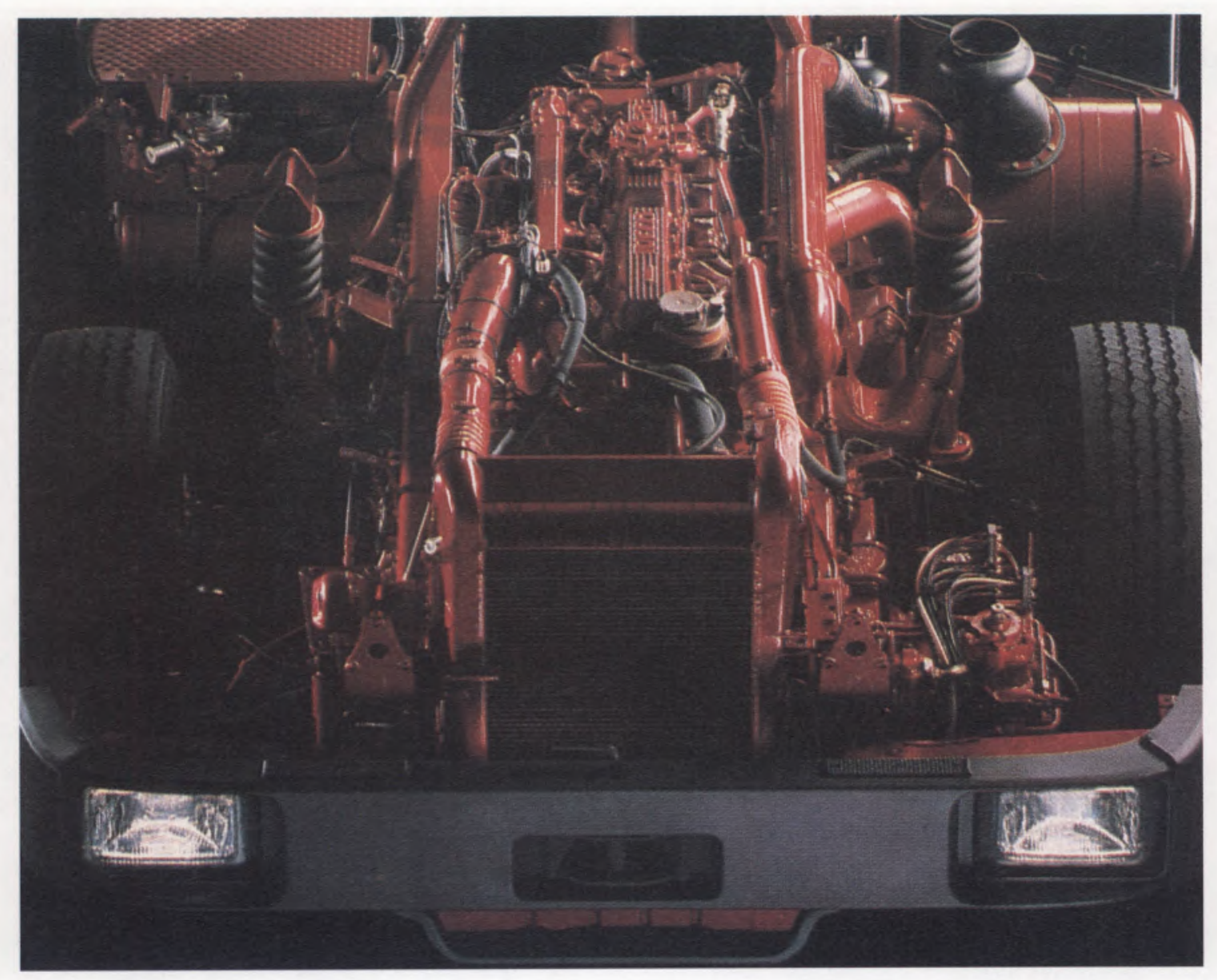

\section{C3V}

Entre as reacções catalíticas que se desenvolveram recentemente, a catálise de póscombustão automóvel ocupa um lugar muito particular. Geralmente, um novo processo resulta de uma pressão económica; pela primeira vez implanta-se um processo à escala mundial por razões puramente ecológicas.

A composição média do gás de escape de um motor de explosão é, em percentagem volumétrica, $\mathrm{CO}_{2}-12,8 ; \mathrm{H}_{2} \mathrm{O}-10,5 ; \mathrm{O}_{2}-1,0 ; \mathrm{NOx}-0,5 ; \mathrm{CO}-2,3 ; \mathrm{N}_{2}-76,0 ; \mathrm{H}_{2}-0,4$ e $\mathrm{HC}-0,1$.

A produção dos gases tóxicos, $\mathrm{CO}, \mathrm{NOx}$ e $\mathrm{HC}$, depende da razão ar/carburante. A função do $\mathrm{C} 3 \mathrm{~V}$, catalisador três vias, é diminuir as percentagens destes poluentes, através das reacções de oxi-redução

$$
\begin{gathered}
\mathrm{HC}+\mathrm{O}_{2} \rightarrow \mathrm{CO}_{2}+\mathrm{H}_{2} \mathrm{O} \\
\mathrm{CO}+\mathrm{O}_{2} \rightarrow \mathrm{CO}_{2} \\
\mathrm{NOx}+\mathrm{CO}+\mathrm{H}_{2} \rightarrow \mathrm{N}_{2}+\mathrm{CO}_{2}+\mathrm{H}_{2} \mathrm{O}
\end{gathered}
$$

para as recomendadas por normas legais (CEE: $\mathrm{CO}-1,25$; $\mathrm{NOx}-0,05$; $\mathrm{HC}-0,03$ )

A. Crucq, "Nouvelles de la Science et des Technologies", 6, 101 (1988) 